\title{
Sex-specific signalling of individual personality by a mutual plumage ornament in a passerine
}

\author{
Attila Fülöp ${ }^{1,2}$ (D) $\cdot$ Dóra Lukács $^{1} \cdot$ Péter Imre Fábián ${ }^{1} \cdot$ Bianka Kocsis $^{1} \cdot$ Gabriella Csöppü $^{1} \cdot$ Judit Bereczki $^{3} \cdot$ Zoltán Barta $^{1}$ (D)
}

Received: 4 November 2020 / Revised: 31 December 2020 / Accepted: 5 January 2021 / Published online: 26 January 2021

(C) The Author(s) 2021

\begin{abstract}
The significance of colour signals in species with strong sexual dimorphism and/or elaborated visual ornaments is rather wellunderstood. Less attention has, however, been devoted to study colour signals in species with weak or no apparent sexual dimorphism. In such species, an interesting possibility arises as both sexes can bear the same colour ornament(s) (i.e. sexes are mutually ornamented), but their signalling value might differ in males and females. We aimed to explore this possibility by investigating the phenotypic correlates of the black bib, a melanin-based plumage ornament, in the Eurasian tree sparrow (Passer montanus). More specifically, we studied the sex-dependent relationships between bib size and three aspects of individuals' phenotype: body condition (i.e. size-corrected body mass), physiology (i.e. cellular innate immunity/inflammation status, expressed through total leucocyte counts, and chronic physiological stress, expressed through the ratio of heterophils to lymphocytes) and individual personality (i.e. activity in a novel environment). We found that bib size was not associated with body condition and cellular innate immunity/inflammation status, but was positively related to physiological stress levels independent of sex. Furthermore, bib size was negatively associated with activity in males but positively in females. Our findings bring important correlative evidence that mutual ornamental traits may have sex-specific signalling value.
\end{abstract}

\section{Significance statement}

The signalling role of elaborated colourful ornaments, that are usually possessed only by males in sexually dimorphic species, is wellestablished. The function of various colour traits which are borne by both sexes (i.e. mutual ornaments), however, is less obvious. Do they have a signalling value in both sexes? If yes, do they signal the same information in males and females? Or, most intriguingly, can they convey different information in the two sexes? To test these alternatives, we studied the signalling value of the black bib, a melanin-based mutual plumage ornament, in Eurasian tree sparrows (Passer montanus). Apart from being correlated with chronic stress in both sexes, bib size was positively related to activity in females but negatively in males. Our results suggest that the information content of the same colour trait in males and females can be different in mutually ornamented species.

Keywords Melanin-based ornament $\cdot$ Personality $\cdot$ Physiology $\cdot$ Melanocortin hypothesis $\cdot$ Phenotypic integration $\cdot$ Passer montanus

Communicated by M. Leonard

\section{Attila Fülöp}

fulop.attila@science.unideb.hu

1 MTA-DE Behavioural Ecology Research Group, Department of Evolutionary Zoology and Human Biology, University of Debrecen, Egyetem tér 1, Debrecen 4032, Hungary

2 Juhász-Nagy Pál Doctoral School, University of Debrecen, Egyetem tér 1, Debrecen 4032, Hungary

3 Department of Evolutionary Zoology and Human Biology, University of Debrecen, Egyetem tér 1, Debrecen 4032, Hungary

\section{Introduction}

Signals are elaborate and costly traits that can function via many modalities, including acoustic (e.g. bird song; Murphy et al. 2008; Nemeth et al. 2012; Baldo et al. 2015), visual (e.g. horns, tusks, various colourful traits; Geist 1966; West and Packer 2002; Tibbetts and Dale 2004; Loyau et al. 2005; Girard and Endler 2014; Graham et al. 2020) or behavioural ones, which combines both acoustic and visual elements (e.g. nuptial dance; McDonald 1989; Lukianchuk and Doucet 2014). Although research in recent decades has accumulated a large amount of information about communication, in 
general, and signalling, in particular, the precise indicator value of traits presumably serving as signals, like colourful ornaments of the integument, is still unknown in many species (e.g. Kemp et al. 2012; Pérez-Rodríguez et al. 2017).

Conspicuous colour signals are usually characteristic of males in sexually dimorphic species, and are frequently used as sexual signs to attract females, which typically have more cryptic colouration (Dale et al. 2015). As a consequence of this common asymmetry between the sexes, there has been a strong bias, ever since Darwin (Darwin 1871), in research interest and effort towards studying species with strong sexual dimorphism, and in particular the role of elaborated ornaments in males in the context of sexual selection (e.g. Pérez i de Lanuza et al. 2013; Seddon et al. 2013; Dale et al. 2015). This phenomenon is well-illustrated by the strongly maleskewed sex ratio found in museum collections from all over the world for both birds and mammals (Cooper et al. 2019). As a result, the adaptive role of female ornaments has been overlooked for a long time, and conspicuous female characters were considered purely as a "by-product" of the shared genome (i.e. genetic correlation) between males and females, but without selection acting on these traits in females (Amundsen 2000). Studies from the last decades (e.g. Amundsen and Forsgren 2001; Jawor et al. 2004; Heinsohn et al. 2005; Komdeur et al. 2005; Weiss 2006, Weiss et al. 2009; Griggio et al. 2010; Baldauf et al. 2011; but see Hill 1993), however, provide considerable evidence that female colouration, similar to that of males, can be adaptive and evolutionary persistent in contexts of sexual (e.g. mate choice, mate competition), social (e.g. competition over nonbreeding resources) or natural selection (e.g. camouflage against predators) (Amundsen 2000; Clutton-Brock 2007; Rosvall 2011; Tobias et al. 2012).

Colour traits, including those serving as signals, can be structurally acquired (Prum 2006) or pigment-based (e.g. carotenoids, melanins; McGraw 2006a, b). Melanins are the most common pigment molecules found in the vertebrate integument and are of two types, eumelanins and pheomelanins, which are responsible for the brown to black and yellow to reddish-brown colourations, respectively (Ducrest et al. 2008). The central mechanism orchestrating melanin synthesis from amino acid precursors (i.e. tyrosine, cysteine) is the so-called melanocortin system (Ducrest et al. 2008). This system consists of the proopiomelanocortin (POMC) gene that produces four different types of melanocortin hormones $(\alpha-$, $\beta$ - and $\gamma$-MSH and $\mathrm{ACTH}$ ) that bind to five different melanocortin receptors (MC1-5R). The main receptor expressed in the integument, thus responsible for colouration, is the MC1R, the other four receptors (MC2-5R) being expressed weakly at the level of skin but having a more important role in other physiological processes in various parts of the body. Overall, the location and hence functions of melanocortin receptors are highly diverse and include skin pigmentation, energy expenditure, stress response, immune capacity and behaviour (Ducrest et al. 2008; San-Jose and Roulin 2018). Eumelanin and pheomelanin are synthesised in different pathways, and the synthesis is controlled by receptor agonists binding to MC1R (Ducrest et al. 2008).

Melanin-based colouration has been found to covary with several phenotypic traits (reviewed by Ducrest et al. 2008; San-Jose and Roulin 2018). One of the possible reasons for this phenomenon is the pleiotropic effects of the genes (see above) regulating the melanin synthesis ("melanocortin hypothesis"; Ducrest et al. 2008). The melanocortin hypothesis thus provides a good mechanistic framework to set up predictions about associations between eumelanic colouration, physiology and behaviour. For instance, according to the melanocortin hypothesis, more eumelanised individuals, due to a higher melanocortin activity, should have a more balanced energy homeostasis (i.e. lower body mass) and a higher immune capacity (i.e. higher anti-inflammatory capacity, lower oxidative stress levels), and should be less sensitive to acute stress (i.e. lower glucocorticoid-mediated stress response) (Ducrest et al. 2008). Moreover, melanin-based colouration should be also correlated with individual behaviour (e.g. aggressiveness; Ducrest et al. 2008).

Behavioural traits are usually consistent within individuals across time and contexts, and this behavioural consistency is defined as individual personality (Dall et al. 2004; Réale et al. 2007). Personality of an individual often mirrors its physiology as well, the two being interrelated, forming different "coping styles" (Groothuis and Carere 2005; Carere et al. 2010). For instance, individuals with different coping styles are characterised by different levels of glucocorticoid-mediated stress responsiveness (e.g. Koolhaas et al. 1999): proactive individuals have a less elevated stress response in risky situations, while reactive individuals are the opposite (Cockrem 2007). Similarly, the coping style of individuals is also linked to their immunity (Koolhaas 2008; Lopes 2017). Furthermore, coping style is also translated into a specific individual behavioural profile. For example, individuals with a more proactive coping style are usually more active, exploratory, aggressive and bold, while reactive individuals are less active, exploratory and aggressive, and more shy (e.g. Barnett et al. 2012; Thys et al. 2017). Therefore, given that the melanocortin machinery is associated with physiology (e.g. stress responsiveness, immunity), melanin-based colouration is also expected to correlate with some of the individual personality traits (e.g. activity, exploration, boldness, aggressiveness), and indeed, previous studies found correlations in multiple instances (e.g. Mafli et al. 2011; Mateos-Gonzalez and Senar 2012; Fargallo et al. 2014; Schweitzer et al. 2015; Thys et al. 2020; but see Nicolaus et al. 2016). Taking all together, a large body of evidence seems to support associations between melanin-based colouration, physiology and behaviour (reviewed in detail by San-Jose and Roulin 2018; but see e.g. Santostefano et al. 2019). It has to 
be noted, though, that correlations between melanin-based colouration and phenotype are not caused exceptionally by gene pleiotropy in the melanocortin system, and several exceptions are known where melanin-based colour variations among individuals (e.g. colour polymorphism) were not explained by the variation of the MC1R gene (e.g. Derelle et al. 2013; Farrell et al. 2015; Riyahi et al. 2015; Corti et al. 2018), suggesting that other mechanisms can also be important.

Melanin-based colouration, by often showing rather complex co-variations with multiple aspects of individuals' phenotype (see above), forms so-called integrated phenotypes (Pigliucci and Preston 2004). Phenotypic integration of colouration can be similar, but can also differ between the sexes, since trait correlations can be shaped by sex-specific selection on life-history profiles and associated physiological (e.g. hormonal) mechanisms (e.g. Stoehr and Kokko 2006; Ketterson et al. 2009), eventually resulting in sex-specific relationships between traits (i.e. stronger phenotypic integration in one of the sexes). For instance, in female fledgling boobies (Sula dactylatra), brown patch size on the head and major wing coverts and testosterone levels were both found to be negatively related to boldness, while in males, these traits were not related (Fargallo et al. 2014). A similar pattern of correlations was found in juvenile kestrels (Falco tinnunculus) as well between plumage blackness and boldness (LópezIdiáquez et al. 2019).

Melanin-based colour traits are exhibited many times as conspicuous visual attributes (e.g. "bagdes of status") which serve as signals in various contexts (i.e. melanin-based signals; Jawor and Breitwisch 2003; McGraw 2008; Roulin 2016). Here, we study melanin-based signalling in the Eurasian tree sparrow (Passer montanus), a species which appears fully monochromatic to the human eye (i.e. males and females look completely similar), but being dichromatic outside the colour spectrum visible to humans, according to a study using avian vision modelling (Eaton 2005). Tree sparrows are mutually ornamented (Kraaijeveld et al. 2007), meaning that both sexes are possessing a black throat patch (hereafter "bib") which is a conspicuous eumelanin-based plumage ornament with demonstrated signalling value in social context during the non-reproductive season (i.e. badge of status; Torda et al. 2004; Mónus et al. 2017): in males, bib size seems to indicate fighting success over both males and females; whereas in females, the social status signalling value of the black bib was not confirmed, although it could not have been excluded (Mónus et al. 2017). Other signalling functions of the bib have not been studied. Nevertheless, the continued expression of the black bib in both sexes, especially in the light of that females in several closely related species lack the black bib (Tibbetts and Safran 2009), leaves open the capacity for a signalling value of the bib in females as well, and also for potential sex-specific effects in the signalling role of this plumage trait.
In this study, we aim to widen our knowledge on the signalling value of the black bib in tree sparrows using the melanocortin hypothesis as a framework (Ducrest et al. 2008). Specifically, we investigate by correlative means whether the size of the bib conveys information, apart from dominance status, about the individuals' body condition (i.e. sizecorrected body mass), physiology (i.e. cellular innate immunity/inflammation status, expressed through total leucocyte counts, and chronic physiological stress, expressed through the ratio of heterophils to lymphocytes) and an axis of personality, namely activity in a novel environment (used at occasions as synonym for exploratory behaviour; Réale et al. 2007; Carter et al. 2013). Based on the melanocortin hypothesis (Ducrest et al. 2008), we predict a positive relationship between bib size and activity, while we predict a negative relationship between bib size, body condition, cellular innate immunity/inflammation status and chronic physiological stress levels. Since phenotypic integration of melanin-based ornamental traits can be similar or different in males and females, we also explore if trait correlations of the black bib differ between the sexes by exploring various scenarios regarding the sex specificity of the investigated phenotypic relationships (Fig. 1).

\section{Methods}

\section{Study site and period}

The study was conducted in the Botanical Garden and the Central Campus of the University of Debrecen (Debrecen, Hungary) during the wintering seasons (i.e. between midOctober and mid-March) of 2016/2017, 2017/2018, 2018/ 2019 and 2019/2020. The study site is mainly an open area with scattered trees and bushes, also containing some buildings of various sizes forming a heterogeneous semi-urban landscape mosaic (Barta et al. 2004; Fülöp et al. 2019).

\section{Field procedures}

Field procedures were similar as described in Fülöp et al.'s study (2019). We captured tree sparrows with mist nets (Ecotone, Poland) at bird feeders each winter between midOctober (after the completion of the annual moult) and late January. Upon capture, we marked all the birds with a uniquely numbered aluminium ring and a unique combination of three plastic colour rings to allow individual identification. Furthermore, we recorded standard biometry of individuals: body mass ( $\pm 0.1 \mathrm{~g}$ with a Pesola spring balance), tarsus length $( \pm 0.01 \mathrm{~mm}$ with a digital calliper) and wing length $( \pm 0.5 \mathrm{~mm}$ with a ruler). We also took a blood sample $(\sim 50-150 \mu \mathrm{l})$ from the brachial vein to determine sex using molecular methods (see below), since sexes cannot be reliably distinguished on the basis of plumage characteristics and/or biometry alone (Mónus 


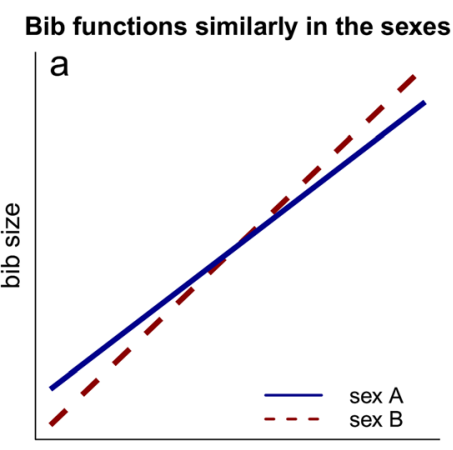

aspect of phenotype
Bib functions differently in the sexes

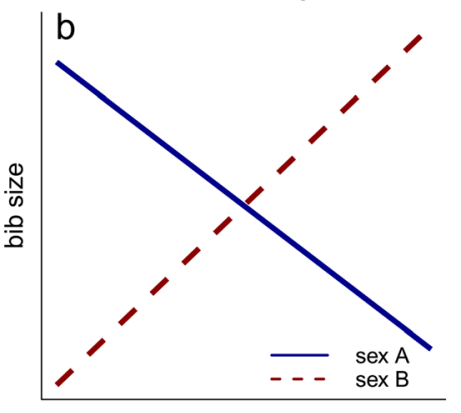

aspect of phenotype
Bib has no signalling function in sex $A$

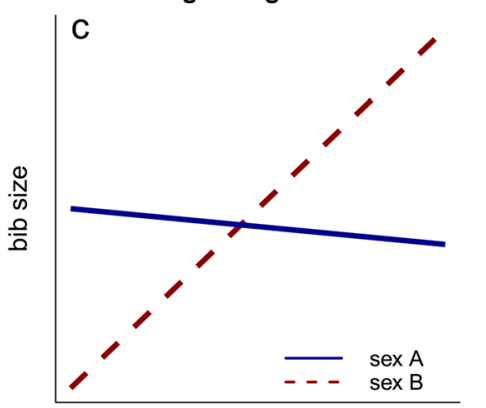

aspect of phenotype

Fig. 1 Predicted relationships between bib size and phenotype in the two sexes under different scenarios. Blue solid and red dashed lines indicate males (sex A) and females (sex B), respectively

et al. 2011). A drop of blood was also used to prepare a blood smear for leukocyte counts (see below). All blood samples were collected within $30 \mathrm{~min}$ after capture $($ mean $=5.33$, median $=$ $3.50, \mathrm{SD}=5.67$, range $=0-26$ ) to exclude the effect of capture stress on blood cell counts (see e.g. Cirule et al. 2012). At capture, we also photographed the black bib of the birds with a digital camera near a standard reference for length (i.e. ruler or millimetre paper), while the birds were held in a standardised position with their head facing the camera so that the axis of the beak was perpendicular to the axis of the body and the camera sensor plane (Fülöp et al. 2019). Finally, each individual was tested for activity (see below). After completing all the procedures, individuals were released at the location of their capture.

During the four seasons of the study, we caught 199 tree sparrows in total (70 males and 129 females). A number of individuals which were used to calculate repeatability of activity (see below) were recaptured and underwent again the same procedure as detailed above. The female-biased sex ratio of our sample can be the result of sex-dependent trapability of individuals or can also represent biased sex ratio in the population (i.e. random sample). Evidence from another population (Kato et al. 2017) shows that in tree sparrows, the mortality of male embryos during incubation can cause a similar femalebiased adult sex ratio, as observed in our population. Therefore, we are reasonably confident that our sample is random, but we are aware that a sampling bias caused by different trapping probability of males and females cannot be excluded completely. Also, it was not possible to record data blind because our study involved focal animals in the field. However, we minimised eventual observer bias in our data as the analysis of the materials and samples collected during fieldwork was carried out by different persons (see below) without prior knowledge on individuals.

\section{Activity test}

The activity of individuals was tested in a mobile test cage, a field-adapted version of the standard open-field test used to quantify exploratory behaviour (see Stuber et al. 2013).
Nevertheless, we prefer to label the behaviour measured in this mobile test cage "activity", since we believe that due to the rather small size of the test cage (see below), the test is more suitable to measure the general level of activity of the individuals rather than exploratory tendency. Moreover, considering also that the behavioural test was carried out at capture, we consider that this measure adequately mirrors the behavioural (acute) stress response of individuals to a risky life event (i.e. trapping; e.g. Martins et al. 2007; Baugh et al. 2013; but see Baugh et al. 2012). It has to be noted though that "activity" and "exploration" are frequently measured using the same test (i.e. open-field test), and the two terms are often used as synonyms (Réale et al. 2007; Carter et al. 2013). The test cage was a $75 \times 45 \times 55(\mathrm{~L} \times \mathrm{W} \times \mathrm{H}) \mathrm{cm}$ solid wooden box of which the front wall $(75 \times 55 \mathrm{~cm})$ was made of transparent wire mesh. The inside space of the test cage was divided into six equal-sized virtual compartments in two rows and three columns which were marked by reference lines traced on the inner walls of the test cage. Three of these virtual compartments (the two upper corners and the lower middle one) contained a perch for each. Individuals were released into the test cage directly from the hands of an experimenter. The behaviour of individuals in the test cage was then videorecorded for 5 min using a video camera (Panasonic HCV510), which was mounted on a tripod and placed at a distance of $1 \mathrm{~m}$ from the wire mesh wall of the cage. While the behaviour of the focal individual was recorded, the experimenter waited quietly on the opposite side of the test cage without disturbing the tested individual. For the same reason, in all seasons, except in 2016/2017, the test cage was visually isolated from the surrounding environment using a camouflage tent, which was installed behind the camera in the front of the cage. The presence or absence of the tent was taken into account during the statistical analyses (see below).

The activity level of individuals was quantified from the video recordings using the "mwrap" event recorder software (Bán et al. 2017). The activity score of each individual was expressed as the total number of position switches between the six compartments of the test cage. We note that, 
although not all the compartments contained perches, birds also frequently used the bottom and the wire mesh wall of the cage to land. Therefore, the number of perches seemingly did not influence the activity pattern of individuals in the test cage. Cases when the bird transited a compartment, but did not land in it (e.g. the upper middle part of the test cage while moving from one upper corner to the other), were also counted as position switches. In total, between 2016 and 2020, we tested 167 individuals (56 males and 111 females) for activity, out of which 23 individuals (6 males and 17 females) were tested more than once (21 individuals twice and 2 individuals three times) in order to calculate the repeatability of activity. Repeated tests were performed only on birds that were recaptured on days different from the day of their first capture. Time spent between tests, expressed in number of days, was as follows: mean $=59.28$, median $=19$, $\mathrm{SD}=115.44$, and range $=2-379$. Out of all ringed individuals, 32 individuals were not tested for activity due to logistical reasons. All videos were analysed by the same person (DL).

\section{Bib size measurements}

The bib size (i.e. area) was measured from digital photographs by using the ImageJ software (ver 1.51i for Linux; https:// imagej.nih.gov/ij/index.html). For each photo, with the "set scale" function, we first calibrated the unit length on the photograph, using the ruler or the millimetre paper, that was also included in the photograph as a reference. Then, with the "freehand selection tool", we traced the outline of the black bib patch, and measured its area $\left(\mathrm{mm}^{2}\right)$ using the "measure" function. The bib area for each individual was measured from the same photo twice, and the values were averaged to increase measurement precision (Fülöp et al. 2019). Repeatability between these two measurements was high (intraclass correlation coefficient, performed with the "ICC" package for R (Wolak et al. 2012; R Core Team 2020): ICC = $0.913,95 \% \mathrm{CI}=0.888-0.933, N=192)$. Bib areas were all measured by the same person (AF).

\section{Leukocyte counts}

The number of leukocytes (i.e. white blood cells; WBC) was counted from blood smears following the method described in Pap et al. (2011). Briefly, blood smears were air-dried, then fixed and coloured using Dia-Fix, Dia-Red and Dia-Blue Panoptic (Diagon Ltd., Hungary). Afterwards, five different types of white blood cells (i.e. heterophils, lymphocytes, monocytes, eosinophils and basophils) were identified and counted under a microscope at $\times 1000$ magnification. Total WBC was expressed as the total number of leukocytes per 10,000 erythrocytes after counting in total 50 leukocyte cells. For the statistical analyses, we used two parameters calculated from leucocyte counts, the total WBC and the ratio of heterophils to lymphocytes (H/L ratio). Total WBC level indicates the cellular innate immune capacity and inflammation status of the organism (Norris and Evans 2000; Salvante 2006), whereas $\mathrm{H} / \mathrm{L}$ ratio reflects chronic physiological stress (Davis et al. 2008; Davis and Maney 2018). H/L ratios have been found to correlate with the intensity of glucocorticoidmediated acute stress response (i.e. corticosterone level; Goessling et al. 2015), however, while corticosterone level tends to decrease over time, even if the stressor persists, the $\mathrm{H} / \mathrm{L}$ ratio seems to remain stable or to even increase (Davis et al. 2008; Goessling et al. 2015; Davis and Maney 2018). Therefore, $\mathrm{H} / \mathrm{L}$ ratio is a more robust marker of chronic physiological stress, resulting especially from ecological stressors (e.g. hunger, parasites; Davis et al. 2008; Goessling et al. 2015; Davis and Maney 2018). Counts were highly repeatable based on a subset of blood smears chosen at random and counted twice (WBC: $\mathrm{ICC}=0.911,95 \% \mathrm{CI}=0.792-0.963$; heterophils: $\mathrm{ICC}=0.931,95 \% \mathrm{CI}=0.837-0.972$; lymphocytes: $\mathrm{ICC}=0.904,95 \% \mathrm{CI}=0.779-0.961 ; \mathrm{H} / \mathrm{L}$ ratio: $\mathrm{ICC}=$ $0.912,95 \% \mathrm{CI}=0.795-0.964 ; N=20$ for each test). All leukocyte counts were carried out by the same person (PIF).

\section{Molecular sexing}

Blood samples were stored without any cryoprotectant at -20 ${ }^{\circ} \mathrm{C}$ until molecular analyses. DNA was extracted by homogenising $5 \mu \mathrm{l}$ of blood in $150 \mu$ l extraction buffer following the protocol described in Bereczki et al. (2014). Molecular sexing was carried out using the $2550 \mathrm{~F}$ and 2718R primers (Fridolfsson and Ellegren 1999) following the amplification protocol in Bereczki et al. (2014). PCR products were loaded on a silver-stained polyacrylamide gel. The electrophoresis buffer systems and running conditions as well as the staining solutions were used according to Bereczki et al. (2005, see Appendix 2, 4a) and An et al. (2009). The identification of different genders was executed based on the banding pattern after visualisation by white light. Molecular sexing was performed by JB and by a laboratory technician (V. Mester).

\section{Statistical analyses}

All calculations and statistical analyses were performed in the R statistical environment version 4.0.3 (R Core Team 2020).

Repeatability of activity level We tested the repeatability of the activity scores using variance partitioning with a linear mixedeffects model (LMM) with Gaussian error distribution ("Imer" function in R, package "Ime4"; Bates et al. 2015) as recommended by Nakagawa and Schielzeth (2010). We built a full model that contained the activity score of the individuals as a dependent variable. Sex (male or female) was entered as a fixed 
factor in the model, while body condition, test date (expressed as the number of days since 1 October of each wintering season), test time (expressed in minutes from midnight) and handling time (expressed as minutes elapsed from capture until the start of the activity test) were included as continuous predictors. Additionally, all second-order interactions of the fixed factor "sex" and other predictors were tested. Individual ID and season were entered as crossed random factors in the model. Since the effect of the tent cannot be statistically separated from the effect of season (i.e. the tent was not used in the first wintering season, but was used in all other seasons), we accounted for the presence or absence of the camouflage tent in the model through the random factor "season". Body condition was characterised using the scaled mass index (SMI; Peig and Green 2009), which is a size-corrected body mass index. SMI was calculated using the body mass and tarsus length data of individuals with the formula: $\mathrm{SMI}=$ body mass $\times$ (mean body mass of the sample/tarsus length $)^{\wedge} b_{\text {SMA }}$, where $b_{\text {SMA }}$ is the slope of a model II standard major axis regression of log mass on log tarsus length, calculated from the sampled individuals ("lmodel2" function in R, package "lmodel2"; Legendre 2018). The activity score of the individuals, and all the continuous predictors included in the model, except SMI, were first square root-transformed to improve their distributional properties and then $Z$-transformed (to have mean $=0, \mathrm{SD}=1$ ) to help model convergence (Schielzeth 2010). The full model was simplified in a stepwise manner (using the "drop1" function in R) by sequentially removing terms with non-significant effects $(P>$ $0.050)$, until reaching the minimal adequate model that included only significant interactions, significant main effects or main effects involved in significant interactions. Significance level $(P)$ of the predictors from the minimal model was tested using the "Anova" function (type II) from the R package "car" (Fox and Weisberg 2019). Post hoc comparisons between different slopes of continuous predictors involved in significant interactions from the minimal model were performed using the $\mathrm{R}$ package "emmeans" (function "emtrends"; Lenth 2020). The repeatability of activity (i.e. adjusted repeatability; $r$ ), the associated standard error (SE), 95\% confidence intervals $(95 \% \mathrm{CI})$ and significance levels ( $P$ and $\left.P_{\text {perm }}\right)$ were calculated following Nakagawa and Schielzeth (2010) using the R package "rptR" with 4999 parametric bootstraps (for the 95\% CI) and 4999 permutation steps (for $P_{\text {perm }}$ ) (function "rptGaussian"; Stoffel et al. 2017).

Bib size and individual phenotypic traits We tested the relationship between bib size and the different phenotypic traits (i.e. body size, SMI, total $\mathrm{WBC}, \mathrm{H} / \mathrm{L}$ ratio and activity) using a LMM with season entered as a random effect with four levels. In this analysis, we used only the data from the first capture of the individuals. Body size index was expressed using predicted values of the first principal component (PC1) extracted using a principal component analysis (PCA; "prcomp" function in R, package "ade4"; Dray and Dufour 2007) that included three biometry measures of individuals: body mass, tarsus length and wing length. PC1 explained $62.13 \%$ of variance and had the following loadings for body mass, tarsus length and wing length, respectively: $0.633,0.593$ and 0.498 . Because we are interested in how bib size might integrate information on different aspect of the phenotype, we first built a full model in which we entered bib size as the dependent variable, while sex was set as a fixed factor, and body size index, SMI, activity score of individuals, total $\mathrm{WBC}$ and $\mathrm{H} / \mathrm{L}$ ratio were entered as continuous predictors. The second-order interactions of the fixed factor "sex" with all the continuous predictors were also included in the model. Since the activity of individuals was significantly influenced by a series of confounding effects (see the "Results" section), but also to minimalize eventual collinearity between predictors, we used the residuals of activity scores extracted from the statistical model we used to test the behavioural repeatability as individual activity scores (i.e. residual activity score) in the subsequent analyses. Prior to entering into the models, all variables with a skewed distribution were transformed to improve model fit (bib size was natural base logtransformed, total $\mathrm{WBC}$ and $\mathrm{H} / \mathrm{L}$ ratio were square root-transformed); and both the dependent variable and the continuous predictors were $Z$-transformed (Schielzeth 2010). The full model was simplified to a minimal adequate model in a similar manner as described above, and the significance level of predictors from the minimal model was tested also in the same way as above presented. The model fit in every case was assessed visually using model diagnostic plots. We note that we omitted one outlier bib size value from the analysis to obtain an adequate model fit (i.e. normality and homoscedasticity of model residuals). Multicollinearity between predictors was excluded as being a potential confounding effect, since all variance inflation factor (VIF) values were less than 5 (e.g. James et al. 2013). Results of both full and minimal models are presented.

\section{Results}

Repeatability of activity level Activity was significantly repeatable (adjusted repeatability for the random factor "individual ID", full model: $r=0.361, \mathrm{SE}=0.138,95 \% \mathrm{CI}=$ $0.216-0.740, P=0.001, P_{\text {perm }}=0.038$; minimal model: $r=$ $0.311, \mathrm{SE}=0.137,95 \% \mathrm{CI}=0.116-0.644, P=0.004, P_{\text {perm }}=$ 0.030 ). Activity was significantly influenced by sex, females being less active than males (Table 1). Furthermore, activity was significantly negatively related to the time of the day when the test was performed (Table 1). Finally, activity and SMI were related in a sex-dependent manner (Table 1, Fig. 2), post hoc tests revealing that males with better body condition (i.e. $\mathrm{SMI})$ were less active $(\beta=-0.262, \mathrm{SE}=0.107, \mathrm{df}=182$, $t=-2.443, P=0.016)$, whereas in females SMI was not related to activity $(\beta=0.041, \mathrm{SE}=0.081, \mathrm{df}=181, t=$ 
Table 1 Results of the linear mixed-effects model on the relationship between individual activity and predictors. For the main effect of the fixed factor "sex", males are included in the intercept, and therefore, the reported estimates show the extent to which females differ from males. The sign of estimates indicates the direction of associations. Significance levels indicate results from likelihood ratio tests (ANOVA, type II). Significant effects $(P \leq 0.050)$ are highlighted in bold. SMI - scaled mass index (body condition)

\begin{tabular}{|c|c|c|c|c|c|c|c|c|c|c|c|c|}
\hline \multirow[b]{2}{*}{ Predictors } & \multicolumn{6}{|c|}{ Full model } & \multicolumn{6}{|c|}{ Minimum adequate model } \\
\hline & Estimate & $\mathrm{SE}$ & $t$ & $\chi^{2}$ & $\mathrm{df}$ & $P$ & Estimate & SE & $t$ & $\chi^{2}$ & df & $P$ \\
\hline Intercept & 0.349 & 0.269 & 1.300 & & & & 0.334 & 0.256 & 1.308 & & & \\
\hline Sex (female) & -0.353 & 0.142 & -2.487 & 4.802 & 1 & 0.028 & -0.344 & 0.139 & -2.472 & 5.455 & 1 & 0.020 \\
\hline SMI & -0.290 & 0.107 & -2.718 & 0.761 & 1 & 0.383 & -0.262 & 0.106 & -2.480 & 1.157 & 1 & 0.282 \\
\hline Test date & -0.024 & 0.113 & -0.212 & 2.353 & 1 & 0.125 & & & & & & \\
\hline Test time within day & -0.254 & 0.123 & -2.062 & 7.698 & 1 & 0.006 & -0.145 & 0.062 & -2.324 & 5.402 & 1 & 0.020 \\
\hline Handling time & 0.003 & 0.131 & 0.023 & 0.666 & 1 & 0.414 & & & & & & \\
\hline Sex (female):SMI & 0.370 & 0.135 & 2.746 & 7.541 & 1 & 0.006 & 0.303 & 0.132 & 2.295 & 5.265 & 1 & 0.022 \\
\hline Sex (female):test date & 0.169 & 0.134 & 1.263 & 1.595 & 1 & 0.207 & & & & & & \\
\hline Sex (female):test time within day & 0.085 & 0.143 & 0.594 & 0.353 & 1 & 0.552 & & & & & & \\
\hline Sex (female):handling time & 0.079 & 0.152 & 0.519 & 0.269 & 1 & 0.604 & & & & & & \\
\hline \multicolumn{13}{|l|}{ Random effects } \\
\hline Residual variance & 0.33 & & & & & & 0.41 & & & & & \\
\hline Individual ID & 0.37 & & & & & & 0.31 & & & & & \\
\hline Season & 0.23 & & & & & & 0.21 & & & & & \\
\hline$N_{\text {individual ID }}$ & 167 & & & & & & 167 & & & & & \\
\hline$N_{\text {season }}$ & 4 & & & & & & 4 & & & & & \\
\hline Observations & 192 & & & & & & 192 & & & & & \\
\hline
\end{tabular}

$0.507, P=0.612)$. Test date, handling time and the interactions of sex with test date, time, and handling time did not influenced activity of individuals (all $P>0.050$; Table 1 ).

Bib size and individual phenotypic traits Bib size was significantly larger in male than in female tree sparrows (Table 2, Fig. 3). Bib size was associated with activity (i.e. residual activity) in a sex-dependent way (Table 2), results of post hoc tests indicating that in males, activity was marginally negatively related to bib size $(\beta=-0.268, \mathrm{SE}=0.137, \mathrm{df}=147, t$ $=-1.957, P=0.052)$, but in females the two were positively associated $(\beta=0.183, \mathrm{SE}=0.090, \mathrm{df}=146, t=2.032, P=$ 0.044; Fig. 4). Furthermore, H/L ratio was significantly positively correlated with bib size, regardless of sex (Table 2, Fig. 5). Body size, SMI and total WBC were not associated with bib size, either independently of or in interaction with sex (Table 2).

\section{Discussion}

We studied the potential signalling value, and its sex dependency, of an eumelanin-based mutual plumage ornament, the black throat patch (i.e. bib), in tree sparrows. We found that bib size was positively related in both sexes to $\mathrm{H} / \mathrm{L}$ ratio (i.e. ratio of heterophils to lymphocytes), a measure characterising

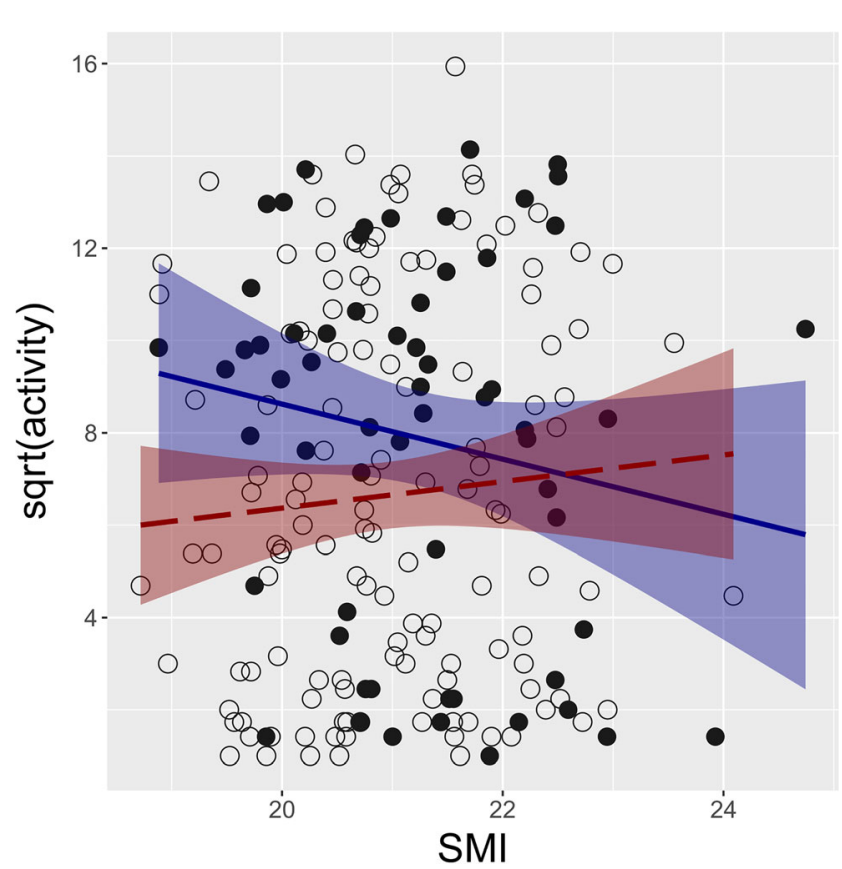

Fig. 2 Sex-dependent relationship between activity (square root) and body condition, expressed through the scaled mass index (SMI), in free-living tree sparrows (Passer montanus). Lines and shaded areas are model-predicted logistic regression lines $\pm 95 \%$ confidence intervals. Filled circles and blue solid line indicate males, while empty circles and red dashed line indicate females 
Table 2 Results of the linear mixed-effects model on the relationship between bib size and aspects of individual phenotype. For the main effect of the fixed factor "sex", males are included in the intercept, and therefore, the reported estimates show the extent to which females differ from males. The sign of estimates indicates the direction of associations.
Significance levels indicate results from likelihood ratio tests (ANOVA, type II). Significant effects $(P \leq 0.050)$ are highlighted in bold. SMI scaled mass index (body condition), total WBC - total number of leukocytes, $\mathrm{H} / \mathrm{L}$ ratio - ratio of heterophils to lymphocytes

\begin{tabular}{|c|c|c|c|c|c|c|c|c|c|c|c|c|}
\hline \multirow[b]{2}{*}{ Predictors } & \multicolumn{6}{|c|}{ Full model } & \multicolumn{6}{|c|}{ Minimum adequate model } \\
\hline & Estimate & SE & $t$ & $\chi^{2}$ & $\mathrm{df}$ & $P$ & Estimate & SE & $t$ & $\chi^{2}$ & df & $P$ \\
\hline Intercept & 0.451 & 0.206 & 2.190 & & & & 0.438 & 0.193 & 2.273 & & & \\
\hline Sex (female) & -0.520 & 0.166 & -3.138 & 8.372 & 1 & 0.004 & -0.545 & 0.157 & -3.470 & 11.765 & 1 & 0.001 \\
\hline Body size & 0.069 & 0.119 & 0.580 & 1.667 & 1 & 0.197 & & & & & & \\
\hline SMI & 0.005 & 0.138 & 0.034 & 0.246 & 1 & 0.620 & & & & & & \\
\hline Activity & -0.290 & 0.133 & -2.185 & 0.401 & 1 & 0.527 & -0.268 & 0.135 & -1.988 & 0.396 & 1 & 0.529 \\
\hline Total WBC & -0.237 & 0.121 & -1.958 & 2.950 & 1 & 0.086 & & & & & & \\
\hline $\mathrm{H} / \mathrm{L}$ ratio & 0.024 & 0.127 & 0.185 & 3.776 & 1 & 0.052 & 0.157 & 0.075 & 2.086 & 4.351 & 1 & $\mathbf{0 . 0 3 7}$ \\
\hline Sex (female):body size & 0.055 & 0.156 & 0.351 & 0.124 & 1 & 0.725 & & & & & & \\
\hline Sex (female):SMI & 0.045 & 0.165 & 0.275 & 0.076 & 1 & 0.783 & & & & & & \\
\hline Sex (female):activity & 0.482 & 0.159 & 3.023 & 9.138 & 1 & 0.003 & 0.451 & 0.161 & 2.791 & 7.792 & 1 & 0.005 \\
\hline Sex (female):total WBC & 0.176 & 0.161 & 1.098 & 1.206 & 1 & 0.272 & & & & & & \\
\hline Sex (female):H/L ratio & 0.188 & 0.157 & 1.198 & 1.434 & 1 & 0.231 & & & & & & \\
\hline \multicolumn{13}{|l|}{ Random effects } \\
\hline Residual variance & 0.74 & & & & & & 0.78 & & & & & \\
\hline Season & 0.09 & & & & & & 0.08 & & & & & \\
\hline$N_{\text {season }}$ & 4 & & & & & & 4 & & & & & \\
\hline Observations & 146 & & & & & & 146 & & & & & \\
\hline
\end{tabular}

chronic physiological stress. Interestingly, the relation between bib size and activity was influenced by sex: while males with larger bib patches were less active, females with larger black bib patches were more active. We found no association between bib size and either SMI (i.e. body condition) or total WBC (i.e. cellular innate immune capacity/inflammation status of the organism).

The melanocortin hypothesis provides a series of predictions for trait correlations between eumelanic colouration and individual phenotype (Ducrest et al. 2008). While some of our results may fit into this framework, for a number of phenotypic measures, we found no relationship with colouration. An interesting prediction of the melanocortin hypothesis is that more eumelanic individuals should be more active (Ducrest et al. 2008). The activity level of an individual, as quantified in the present study, might mirror both its physiological state (e.g. acute stress response to capture), but also other aspects of its personality (e.g. exploration, boldness). More eumelanised individuals are expected to be more resistant to acute stress, since melanocortins are involved in the modulation of glucocorticoid-mediated stress response (Ducrest et al. 2008); and more eumelanised individuals have been shown to be more active, exploratory, aggressive and bold (e.g. Mafli et al. 2011; Mateos-Gonzalez and Senar 2012; Schweitzer et al. 2015; Thys et al. 2020; but see Nicolaus et al. 2016). Therefore, we might reasonably expect more eumelanised individuals to be also more active. Our findings apparently

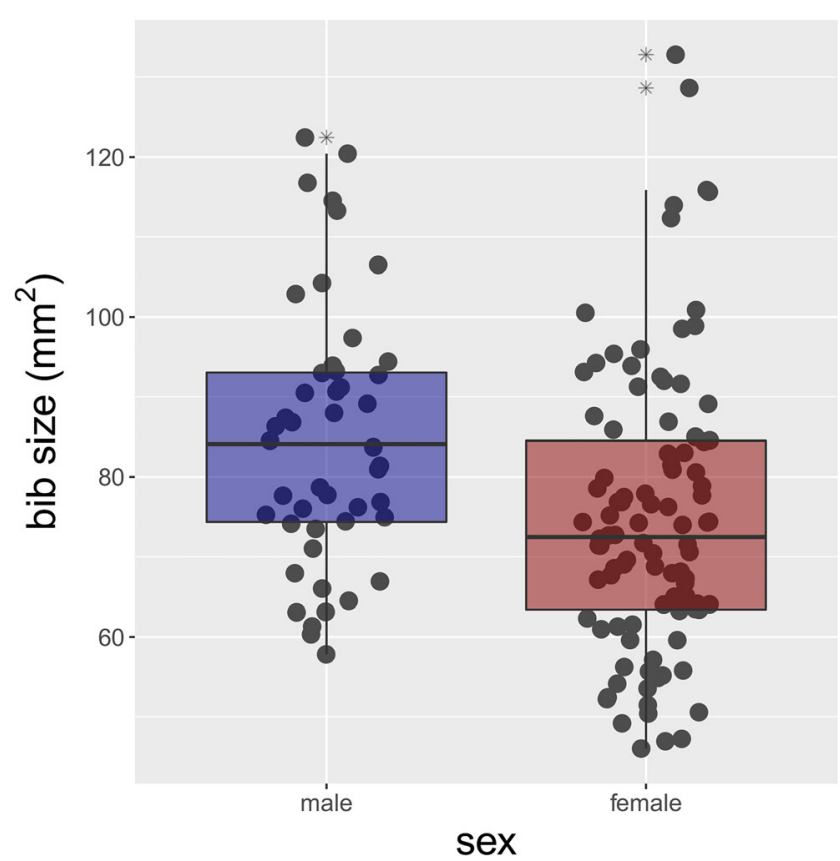

Fig. 3 Boxplot showing the sex differences in bib size in free-living tree sparrows (Passer montanus). Horizontal bold lines indicate median values, box margins mark the $25 \%$ and $75 \%$ quartiles, while whiskers show the lower and upper range values, excluding outliers (i.e. values outside 1.5 times the interquartile range above the upper quartile and below the lower quartile), which are denoted by asterisks. The blue box indicates males, while the red box indicates females. Points denote individual values that are jittered to reduce overlaps of data points on the plot 


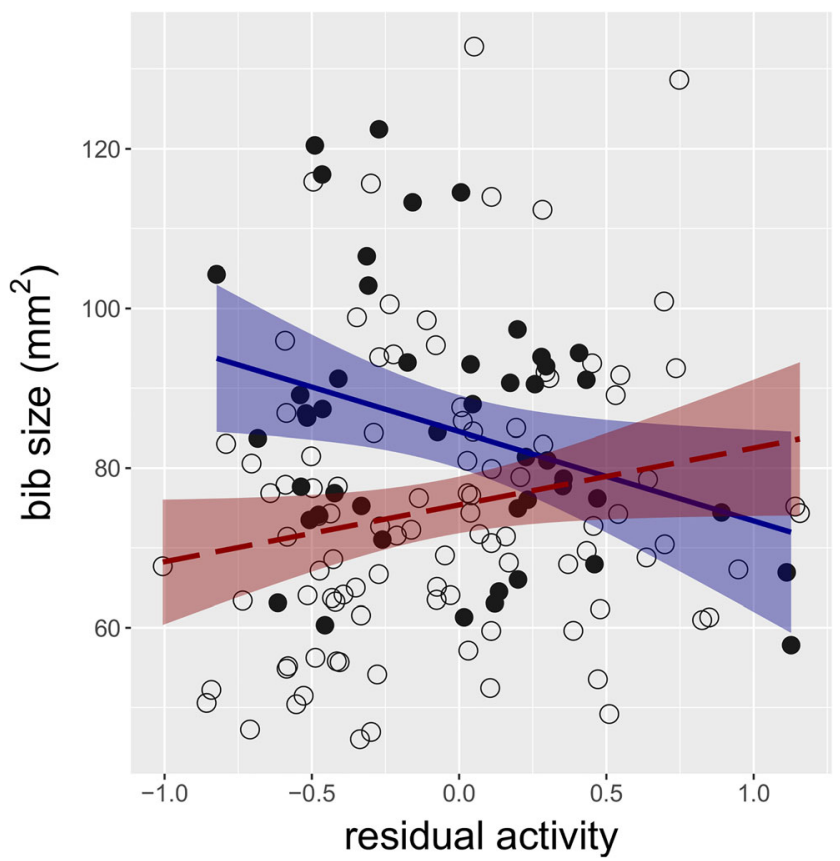

Fig. 4 Sex-dependent relationship between activity (i.e. residual activity) and bib size in free-living tree sparrows (Passer montanus). Lines and shaded areas are model-predicted logistic regression lines \pm 95\% confidence intervals. Filled circles and blue solid line indicate males, while empty circles and red dashed line indicate females

contradict this prediction, at least in part, since we found different relationships between bib size and activity in males and females. The sex-specific relationships between activity and bib size we identified (i.e. negative in males and positive in females) raise several questions. First, what proximate mechanisms might be responsible for this difference between the two sexes? Second, why do females and males advertise their personality differently in this species? In other words, does signalling activity levels differently in the two sexes have an adaptive value?

Phenotypic traits, including colouration, often covary with each other forming integrated phenotypes (Pigliucci and Preston 2004). Mechanistically, covariation between traits is usually the result of a shared physiological mechanism determining trait expression, for instance, when the expression of multiple phenotypic traits is mediated by the same hormone (Ketterson et al. 2009). Hormones, however, can have weaker or stronger effects on the expression of different traits, due to differing circulating hormone concentrations or sensitivity of target tissues, which might result in low or high phenotypic integration (Ketterson et al. 2009). For example, in males and females, trait correlations might be altered by gonadal hormones (e.g. testosterone), which have been found to influence sex-specific trait covariances (e.g. pace-of-life syndrome; Immonen et al. 2018). Melanocortins and sex hormone (e.g. testosterone) production are linked to each other (Ducrest et al. 2008) and might thus have sex-specific consequences in terms of colour-related trait correlations (e.g. Fargallo et al. 2014). Furthermore, since some hormone levels, for instance that of testosterone, can strongly vary seasonally (e.g. Van Duyse et al. 2003; Laucht et al. 2010), trait correlations mediated by testosterone might also change between seasons and correlational patterns can differ to those reported in this study, which were found during winter.

Why do males and females signal their activity differently? Sex-dependent associations between phenotypic traits, including behaviour, might be the result of adaptations to differences in social context. For instance, in great tits Dingemanse and de Goede (2004) found context-dependent relationship between exploration and dominance (the latter is signalled in great tits by their black "tie"). More dominant territory-holding adults were also more exploratory, while in juvenile, non-territorial birds, the relationship was reversed, with more dominant individuals being less exploratory. Tree sparrows form large flocks during the winter (Summers-Smith 1995; Mónus and Barta 2010); therefore, the most relevant context shaping trait correlations in this species during this period might, at least partly, be related to aspects of social behaviour (e.g. sex roles within the group, social dominance status, group composition). Sexspecific associations between phenotypic traits are already known in this species from previous studies (e.g. dominance signalling, Mónus et al. 2017; determinants of social foraging tactic use, Fülöp et al. 2019), and these suggest that males and females may use distinct behavioural strategies in various social

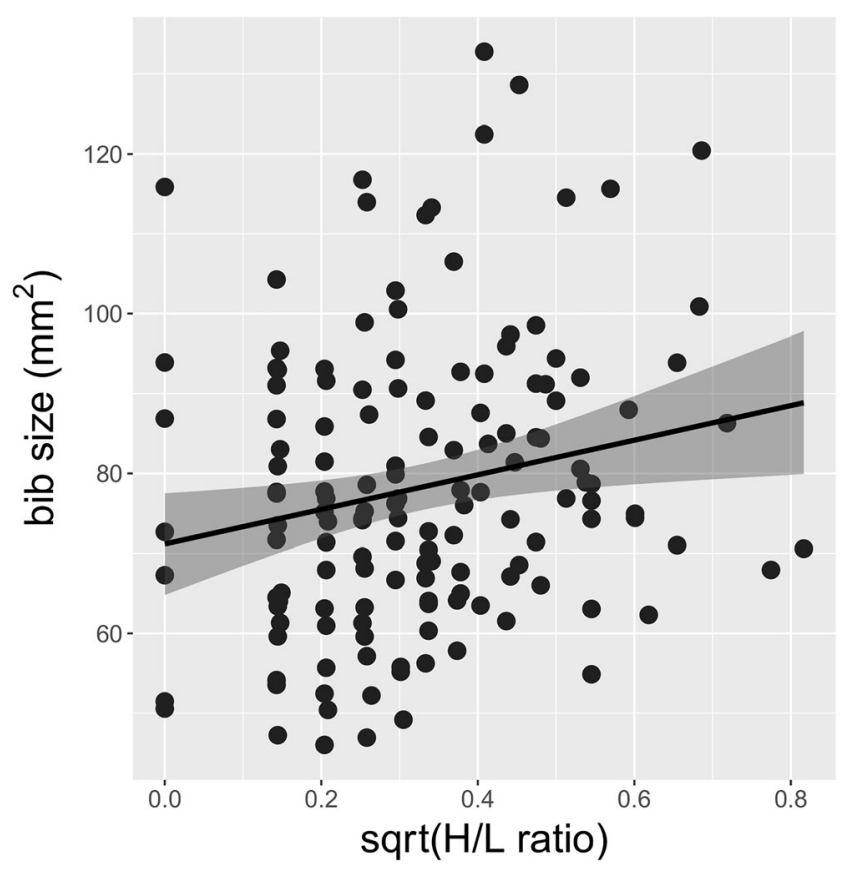

Fig. 5 Relationship between the ratio of heterophils to lymphocytes (square root of $\mathrm{H} / \mathrm{L}$ ratio) and bib size in free-living tree sparrows (Passer montanus). The black line and the shaded area are the modelpredicted logistic regression line $\pm 95 \%$ confidence interval 
situations. As a consequence, the signalling role of mutual plumage ornaments, and implicitly trait correlations, might evolve in sex-specific ways. Moving beyond, though, the question of why to signal individual personality still remains open. Previously, we have found that personality is related to social foraging tactic use in this species (Fülöp et al. 2019), suggesting that signalling individual personality can be meaningful, at least in this context. Still, we acknowledge that a significant correlation between bib size and activity does not necessarily signify a direct causal link between the two traits and can have other (e.g. genetic) causes (San-Jose and Roulin 2018).

The melanocortin hypothesis also predicts that more eumelanised individuals should have a higher immune capacity (i.e. better anti-inflamatory capacity, more resistant to oxidative stress; Ducrest et al. 2008). We found no relationship between bib size and total WBC (i.e. cellular innate immunity/ inflammation status), but found a positive association of bib size with $\mathrm{H} / \mathrm{L}$ ratio (i.e. chronic physiological stress). $\mathrm{H} / \mathrm{L}$ ratios adequately indicate individual physiological responses to various internal and/or external stressors (e.g. hunger, parasites; Davis et al. 2008; Davis and Maney 2018) and tend to remain stable over time; thus, $\mathrm{H} / \mathrm{L}$ ratios mirror long-lasting exposure to stressful stimuli (Davis et al. 2008; Goessling et al. 2015; Davis and Maney 2018). The positive relationship between bib size and $\mathrm{H} / \mathrm{L}$ ratio is inconsistent with most of the earlier studies (e.g. Minias et al. 2014, 2019; Moore et al. 2015; Svobodová et al. 2018; but see e.g. Svobodová et al. 2013). One possible interpretation of this positive relationship between bib size and $\mathrm{H} / \mathrm{L}$ ratio is that individuals with large bibs might be involved in a higher number of agonistic interactions which might result in higher physiological stress levels, a cost of social dominance (Davis et al. 2008).

Finally, according to the melanocortin hypothesis, more eumelanised individuals should have a lower body mass, since melanocortins reduce food intake, the amount of adipose tissue, and increase metabolic rate and physical activity (Ducrest et al. 2008). We found no correlation between bib size and body condition (i.e. an index of body reserves). Our results are in contrast with some previous studies reporting either positive or negative relationship between melanin-based colouration and body mass and/or body condition (e.g. Kingma et al. 2008; Roulin 2009; Kim et al. 2013; Moore et al. 2015; reviewed by Roulin 2009, 2016; Guindre-Parker and Love 2014), but are in line with many others where no such relationship was found (e.g. Järvi and Bakken 1984; Jawor et al. 2004; reviewed by Roulin 2009). This diversity of results suggests that the relationship between melanic colouration and condition might not be a simple one (see also San-Jose and Roulin 2018). Indeed, the relationship between body reserves and melanin-based colouration can be confounded by several environmental factors (e.g. food availability; Roulin 2009), but can have genetic bases as well (see discussion in Roulin 2009).
To summarise, our study provides rather intriguing results which bring only a weak support for the melanocortin hypothesis. Although we found significant correlations between activity (i.e. a measure of personality) and eumelanin-based colouration, and chronic physiological stress levels and eumelanic colouration, respectively, both relationships were contrasting to what we predicted based on the melanocortin hypothesis. Several studies seem to support the melanocortin hypothesis (reviewed by Ducrest et al. 2008; San-Jose and Roulin 2018), but some others, similarly to our study, failed to detect expected trait correlations (e.g. Santostefano et al. 2019). Our findings in tree sparrows, however, show that, interestingly, some correlations between melanin-based colouration and individual phenotypic traits might vary according to sex, indicating that the signalling function of melanin traits in males and females might be different, at least in this species. Nevertheless, the role of melanin signals in mutually ornamented species and the mechanisms responsible for the emergence and evolutionary maintenance of sexdependent signal information content in such species still require further investigations.

Acknowledgements We thank Zoltán Németh and several undergraduate students for their assistance in capturing tree sparrows. We are also deeply grateful to Valéria Mester for her contribution to molecular sexing, András Kosztolányi for his advises on statistical analyses, Miklós Bán for his technical help, and László Papp and the staff of the Botanical Garden for their support. We are indebted to Veronika Bókony, Gergely Hegyi and two anonymous reviewers for their constructive comments on an earlier version of the manuscript. Grant $\mathrm{C}$. McDonald provided further valuable comments and kindly improved the English language on the manuscript.

Authors' contributions $\mathrm{AF}$ and $\mathrm{ZB}$ conceived and designed the study. $\mathrm{AF}, \mathrm{DL}, \mathrm{PIF}, \mathrm{BK}, \mathrm{GC}$ and $\mathrm{ZB}$ collected the data. JB performed the molecular sexing. $\mathrm{AF}$ and $\mathrm{ZB}$ analysed the data. $\mathrm{AF}$ wrote the manuscript with significant input from ZB. All authors contributed critically to the drafts and gave final approval for publication.

Funding Open Access funding provided by University of Debrecen. This work was supported by the National Research, Development and Innovation Office of Hungary (grant number K112527 to ZB). AF was supported by a $\mathrm{PhD}$ scholarship and a scholarship from the Magyar Vidékért (Pro Regione) Foundation. The work/publication is supported by the EFOP-3.6.1-16-2016-00022 project. The project is co-financed by the European Union and the European Social Fund. The research was financed by the Higher Education Institutional Excellence Programme (NKFIH-1150-6/2019) of the Ministry of Innovation and Technology in Hungary, within the framework of the DE-FIKP Behavioural Ecology Research Group thematic programme of the University of Debrecen.

Data availability The datasets generated and/or analysed during the current study are available from the corresponding author on reasonable request.

\section{Compliance with ethical standards}

Conflict of interest The authors declare that they have no conflicts of interest. 
Ethical approval Tree sparrows were ringed under a licence from the Hungarian Bird Ringing Center (licence nr. 390 accredited to ZB) and permission for the study was granted by the Hajdú-Bihar County Governmental Office, District Office of Debrecen - Department of Environmental and Nature Protection (permit nr. HB/10-KTF/00487-1/ 2016). The study complies with the European laws regarding animal welfare and adheres to the ASAB/ABS guidelines for the use of animals in behavioural research.

Open Access This article is licensed under a Creative Commons Attribution 4.0 International License, which permits use, sharing, adaptation, distribution and reproduction in any medium or format, as long as you give appropriate credit to the original author(s) and the source, provide a link to the Creative Commons licence, and indicate if changes were made. The images or other third party material in this article are included in the article's Creative Commons licence, unless indicated otherwise in a credit line to the material. If material is not included in the article's Creative Commons licence and your intended use is not permitted by statutory regulation or exceeds the permitted use, you will need to obtain permission directly from the copyright holder. To view a copy of this licence, visit http://creativecommons.org/licenses/by/4.0/.

\section{References}

Amundsen T (2000) Why are female birds ornamented? Trends Ecol Evol 15:149-155

Amundsen T, Forsgren E (2001) Male mate choice selects for female coloration in a fish. P Natl Acad Sci USA 98:13155-13160

An ZW, Xie LL, Cheng H, Zhou Y, Zhang Q, He XG, Huang HS (2009) A silver staining procedure for nucleic acids in polyacrylamide gels without fixation and pretreatment. Anal Biochem 391:77-79

Baldauf SA, Bakker TCM, Kullmann H, Thünken T (2011) Female nuptial coloration and its adaptive significance in a mutual mate choice system. Behav Ecol 22:478-485

Baldo S, Mennill DJ, Guindre-Parker S, Gilchrist HG, Love OP (2015) The oxidative cost of acoustic signals: examining steroid versus aerobic activity hypotheses in a wild bird. Ethology 121:1081-1090

Barnett CA, Thompson CF, Sakaluk SK (2012) Aggressiveness, boldness and parental food provisioning in male house wrens (Troglodytes aedon). Ethology 118:984-993

Barta Z, Liker A, Mónus F (2004) The effects of predation risk on the use of social foraging tactics. Anim Behav 67:301-308

Bates D, Maechler M, Bolker B, Walker S (2015) Fitting linear mixedeffects models using lme4. J Stat Softw 67:1-48

Baugh AT, Schaper SV, Hau M, Cockrem JF, de Goede P, van Oers K (2012) Corticosterone responses differ between lines of great tits (Parus major) selected for divergent personalities. Gen Comp Endocrinol 175:488-494

Baugh AT, van Oers K, Naguib M, Hau M (2013) Initial reactivity and magnitude of the acute stress response associated with personality in wild great tits (Parus major). Gen Comp Endocrinol 189:96-104

Bán M, Földvári M, Babits M, Barta Z (2017) Simple command-line open-source software to analyse behavioural observation video recordings. Acta Zool Acad Sci Hung 63:137-142

Bereczki J, Pecsenye K, Peregovits L, Varga Z (2005) Pattern of genetic differentiation in the Maculinea alcon species group (Lepidoptera, Lycaenidae) in Central Europe. J Zool Syst Evol Res 43:157-165

Bereczki J, Tóth JP, Sramkó G, Varga Z (2014) Multilevel studies on the two phenological forms of Large Blue (Maculinea arion) (Lepidoptera: Lycaenidae). J Zool Syst Evol Res 52:32-43

Carere C, Caramaschi D, Fawcett TW (2010) Covariation between personalities and individual differences in coping with stress: converging evidence and hypotheses. Curr Zool 56:728-740
Carter AJ, Feeney WE, Marshall HH, Cowlishaw G, Heinsohn R (2013) Animal personality: what are behavioural ecologists measuring? Biol Rev 88:465-475

Cïrule D, Krama T, Vrublevska J, Rantala MJ, Krams I (2012) A rapid effect of handling on counts of white blood cells in a wintering passerine bird: a more practical measure of stress? J Ornithol 153: $161-166$

Clutton-Brock T (2007) Sexual selection in males and females. Science 318:1882-1885

Cockrem JF (2007) Stress, corticosterone responses and avian personalities. J Ornithol 148:169-178

Cooper N, Bond AL, Davis JL, Portela Miguez R, Tomsett L, Helgen KM (2019) Sex biases in bird and mammal natural history collections. Proc R Soc B 286:20192025

Corti M, Podofillini S, Griggio M, Gianfranceschi L, Ducrest AL, Roulin A, Cecere JG, Saino N, Rubolini D (2018) Sequence variation in melanocortin-1-receptor and tyrosinase-related protein 1 genes and their relationship with melanin-based plumage trait expression in Lesser Kestrel (Falco naumanni) males. J Ornithol 159:587-591

Dale J, Dey CJ, Delhey K, Kempenaers B, Valcu M (2015) The effects of life history and sexual selection on male and female plumage colouration. Nature 527:367-370

Dall SR, Houston AI, McNamara JM (2004) The behavioural ecology of personality: consistent individual differences from an adaptive perspective. Ecol Lett 7:734-739

Darwin C (1871) The descent of man, and selection in relation to sex. John Murray, London

Davis AK, Maney DL (2018) The use of glucocorticoid hormones or leucocyte profiles to measure stress in vertebrates: what's the difference? Methods Ecol Evol 9:1556-1568

Davis AK, Maney DL, Maerz JC (2008) The use of leukocyte profiles to measure stress in vertebrates: a review for ecologists. Funct Ecol 22: $760-772$

Derelle R, Kondrashov FA, Arkhipov VY, Corbel H, Frantz A, Gasparini J, Jacquin L, Jacob G, Thibault S, Baudry E (2013) Color differences among feral pigeons (Columba livia) are not attributable to sequence variation in the coding region of the melanocortin-1 receptor gene (MC1R). BMC Res Notes 6:310

Dingemanse NJ, de Goede P (2004) The relation between dominance and exploratory behavior is context-dependent in wild great tits. Behav Ecol 15:1023-1030

Dray S, Dufour AB (2007) The ade4 package: implementing the duality diagram for ecologists. J Stat Softw 22:1-20

Ducrest AL, Keller L, Roulin A (2008) Pleiotropy in the melanocortin system, coloration and behavioural syndromes. Trends Ecol Evol 23:502-510

Eaton MD (2005) Human vision fails to distinguish widespread sexual dichromatism among sexually "monochromatic" birds. P Natl Acad Sci USA 102:10942-10946

Fargallo JA, Velando A, López-Rull I, Gañán N, Lifshitz N, Wakamatsu $\mathrm{K}$, Torres R (2014) Sex-specific phenotypic integration: endocrine profiles, coloration, and behavior in fledgling boobies. Behav Ecol 25:76-87

Farrell LL, Küpper C, Burke T, Lank DB (2015) Major breeding plumage color differences of male ruffs (Philomachus pugnax) are not associated with coding sequence variation in the MC1R gene. J Hered 106:211-215

Fox J, Weisberg S (2019) An R companion to applied regression, 3rd edn. Sage, Thousand Oaks

Fridolfsson A-K, Ellegren H (1999) A simple and universal method for molecular sexing of non-ratite birds. J Avian Biol 30:116-121

Fülöp A, Németh Z, Kocsis B, Deák-Molnár B, Bozsoky T, Barta Z (2019) Personality and social foraging tactic use in free-living Eurasian tree sparrows (Passer montanus). Behav Ecol 30:894-903

Geist V (1966) The evolutionary significance of mountain sheep horns. Evolution 20:558-566 
Girard MB, Endler JA (2014) Peacock spiders. Curr Biol 24:R588-R590 Goessling JM, Kennedy H, Mendonça MT, Wilson AE (2015) A metaanalysis of plasma corticosterone and heterophil:lymphocyte ratiosis there conservation of physiological stress responses over time? Funct Ecol 29:1189-1196

Graham ZA, Garde E, Heide-Jørgensen MP, Palaoro AV (2020) The longer the better: evidence that narwhal tusks are sexually selected. Biol Lett 16:20190950

Griggio M, Zanollo V, Hoi H (2010) Female ornamentation, parental quality, and competitive ability in the rock sparrow. J Ethol 28: 455-462

Groothuis TGG, Carere C (2005) Avian personalities: characterization and epigenesis. Neurosci Biobehav Rev 29:137-150

Guindre-Parker S, Love OP (2014) Revisiting the condition-dependence of melanin-based plumage. J Avian Biol 45:29-33

Heinsohn R, Legge S, Endler JA (2005) Extreme reversed sexual dichromatism in a bird without sex role reversal. Science 309:617-619

Hill GE (1993) Male mate choice and the evolution of female plumage coloration in the house finch. Evolution 47:1515-1525

Immonen E, Hämäläinen A, Schuett W, Tarka M (2018) Evolution of sex-specific pace-of-life syndromes: genetic architecture and physiological mechanisms. Behav Ecol Sociobiol 72:60

James G, Witten D, Hastie T, Tibshirani R (2013) An introduction to statistical learning. Springer, NY

Jawor JM, Breitwisch R (2003) Melanin ornaments, honesty, and sexual selection. Auk 120:249-265

Jawor JM, Gray N, Beall SM, Breitwisch R (2004) Multiple ornaments correlate with aspects of condition and behaviour in female Northern Cardinals, Cardinalis cardinalis. Anim Behav 67:875-882

Järvi T, Bakken M (1984) The function of the variation in the breast stripe of the great tit (Parus major). Anim Behav 32:590-596

Kato T, Matsui S, Terai Y, Tanabe H, Hashima S, Kasahara S, Morimoto G, Mikami OK, Ueda K, Kutsukake N (2017) Male-specific mortality biases secondary sex ratio in Eurasian tree sparrows Passer montanus. Ecol Evol 7:10675-10682

Kemp DJ, Herberstein ME, Grether GF (2012) Unraveling the true complexity of costly color signaling. Behav Ecol 23:233-236

Ketterson ED, Atwell JW, McGlothlin JW (2009) Phenotypic integration and independence: hormones, performance, and response to environmental change. Integr Comp Biol 49:365-379

Kim S-Y, Fargallo JA, Vergara P, Martinez-Padilla J (2013) Multivariate heredity of melanin-based coloration, body mass and immunity. Heredity 111:139-146

Kingma SA, Szentirmai I, Székely T, Bókony V, Bleeker M, Liker A, Komdeur J (2008) Sexual selection and the function of a melaninbased plumage ornament in polygamous penduline tits Remiz pendulinus. Behav Ecol Sociobiol 62:1277-1288

Komdeur J, Oorebeek M, van Overveld T, Cuthill IC (2005) Mutual ornamentation, age, and reproductive performance in the European starling. Behav Ecol 16:805-817

Koolhaas JM (2008) Coping style and immunity in animals: making sense of individual variation. Brain Behav Immun 22:662-667

Koolhaas JM, Korte SM, de Boer SF, van der Vegt BJ, van Reenen CG, Hopster H, de Jong IC, Ruis MAW, Blokhuis HJ (1999) Coping styles in animals: current status in behavior and stress-physiology. Neurosci Biobehav Rev 23:925-935

Kraaijeveld K, Kraaijeveld-Smit FJL, Komdeur J (2007) The evolution of mutual ornamentation. Anim Behav 74:657-677

Laucht S, Kempenaers B, Dale J (2010) Bill color, not badge size, indicates testosterone-related information in house sparrows. Behav Ecol Sociobiol 64:1461-1471

Legendre P (2018) lmodel2: model II regression. R package version 1.73, https://CRAN.R-project.org/package=lmodel2

Lenth R (2020) emmeans: Estimated marginal means, aka least-squares means. R package version 1.5.3, https://CRAN.R-project.org/ package $=$ emmeans
Lopes PC (2017) Why are behavioral and immune traits linked? Horm Behav 88:52-59

López-Idiáquez D, Fargallo JA, López-Rull I, Martínez-Padilla J (2019) Plumage coloration and personality in early life: sexual differences in signalling. Ibis 161:216-221

Loyau A, Saint Jalme M, Cagniant C, Sorci G (2005) Multiple sexual advertisements honestly reflect health status in peacocks (Pavo cristatus). Behav Ecol Sociobiol 58:552-557

Lukianchuk KC, Doucet SM (2014) Cooperative courtship display in Long-tailed Manakins Chiroxiphia linearis: predictors of courtship success revealed through full characterization of display. J Ornithol 155:729-743

Mafli A, Wakamatsu K, Roulin A (2011) Melanin-based coloration predicts aggressiveness and boldness in captive eastern Hermann's tortoises. Anim Behav 81:859-863

Martins TL, Roberts ML, Giblin I, Huxham R, Evans MR (2007) Speed of exploration and risk-taking behavior are linked to corticosterone titres in zebra finches. Horm Behav 52:445-453

Mateos-Gonzalez F, Senar JC (2012) Melanin-based trait predicts individual exploratory behaviour in siskins, Carduelis spinus. Anim Behav 83:229-232

McDonald DB (1989) Correlates of male mating success in a lekking bird with male-male cooperation. Anim Behav 37:1007-1022

McGraw KJ (2006a) Mechanisms of carotenoid-based coloration. In: Hill GE, McGraw KJ (eds) Bird coloration: mechanisms and measurements. Harvard University Press, Cambridge, pp 177-242

McGraw KJ (2006b) Mechanisms of melanin-based coloration. In: Hill GE, McGraw KJ (eds) Bird Coloration: Mechanisms and Measurements. Harvard University Press, Cambridge, pp 243-294

McGraw KJ (2008) An update on the honesty of melanin-based color signals in birds. Pigm Cell Melanoma Res 21:133-138

Minias P, Kaczmarek K, Włodarczyk R, Janiszewski T (2014) Melaninbased coloration covaries with fluctuating asymmetry, nutritional state and physiological stress response in common snipe. J Avian Biol 45:51-58

Minias P, Indykiewicz P, Nowakowski JJ, Ledwoń M, Kowalski J, Betleja J, Dulisz B, Chyb A, Janiszewski T (2019) Melanin-based plumage ornamentation signals condition and physiological stress in the black-headed gull. J Ornithol 160:1159-1169

Mónus F, Barta Z (2010) Seasonality and sociality in tree sparrows Passer montanus. Int Stud Sparrows 34:18-22

Mónus F, Liker A, Pénzes Z, Barta Z (2017) Status signalling in male but not in female Eurasian Tree Sparrows Passer montanus. Ibis 159: $180-192$

Mónus F, Szabó K, Lózsa A, Pénzes Z, Barta Z (2011) Intersexual size and plumage differences in tree sparrows (Passer montanus) - a morphological study based on molecular sex determination. Acta Zool Acad Sci H 57:269-276

Moore FR, Cīrule D, Kivleniece I, Vrublevska J, Rantala MJ, Sild E, Sepp T, Hõrak P, Krama T, Krams I (2015) Investment in a sexual signal results in reduced survival under extreme conditions in the male great tit (Parus major). Behav Ecol Sociobiol 69:151-158

Murphy MT, Sexton K, Dolan AC, Redmond LJ (2008) Dawn song of the eastern kingbird: an honest signal of male quality? Anim Behav 75:1075-1084

Nakagawa S, Schielzeth H (2010) Repeatability for Gaussian and nonGaussian data: a practical guide for biologists. Biol Rev 85:935-956

Nemeth E, Kempenaers B, Matessi G, Brumm H (2012) Rock sparrow song reflects male age and reproductive success. PLoS ONE 7: e43259

Nicolaus M, Piault R, Ubels R, Tinbergen JM, Dingemanse NJ (2016) The correlation between coloration and exploration behaviour varies across hierarchical levels in a wild passerine bird. J Evol Biol 29: 1780-1792

Norris K, Evans MR (2000) Ecological immunology: life history tradeoffs and immune defense in birds. Behav Ecol 11:19-26 
Pap PL, Vágási CI, Czirják GÁ, Titilincu A, Pintea A, Osváth G, Fülöp A, Barta $Z$ (2011) The effect of coccidians on the condition and immune profile of molting house sparrows (Passer domesticus). Auk 128:330-339

Peig J, Green AJ (2009) New perspectives for estimating body condition from mass/length data: the scaled mass index as an alternative method. Oikos 118:1883-1891

Pérez i de Lanuza G, Font E, Monterde JL (2013) Using visual modelling to study the evolution of lizard coloration: sexual selection drives the evolution of sexual dichromatism in lacertids. J Evol Biol 26:18261835

Pérez-Rodríguez L, Jovani R, Stevens M (2017) Shape matters: animal colour patterns as signals of individual quality. Proc R Soc B 284: 20162446

Pigliucci M, Preston K (2004) Phenotypic integration: studying the ecology and evolution of complex phenotypes. Oxford University Press, Oxford

Prum RO (2006) Anatomy, physics and evolution of avian structural colors. In: Hill GE, McGraw KJ (eds) Bird coloration: mechanisms and measurements. Harvard University Press, Cambridge, pp 295 353

R Core Team (2020) R: a language and environment for statistical computing. R Foundation for Statistical Computing, Vienna http://www. R-project.org/

Réale D, Reader SM, Sol D, McDougall PT, Dingemanse NJ (2007) Integrating animal temperament within ecology and evolution. Biol Rev 82:291-318

Rosvall KA (2011) Intrasexual competition in females: evidence for sexual selection? Behav Ecol 22:1131-1140

Roulin A (2009) Covariation between eumelanic pigmentation and body mass only under specific conditions. Naturwissenschaften 96:375382

Roulin A (2016) Condition-dependence, pleiotropy and the handicap principle of sexual selection in melanin-based colouration. Biol Rev 91:328-348

Riyahi S, Björklund M, Ödeen A, Senar JC (2015) No association between the melanocortin-1 receptor (MC1R) and black belly stripe size variation in the Great Tit Parus major. Bird Study 62:150-152

Salvante KG (2006) Techniques for studying integrated immune function in birds. Auk 123:575-586

San-Jose LM, Roulin A (2018) Toward understanding the repeated occurrence of associations between melanin-based coloration and multiple phenotypes. Am Nat 192:111-130

Santostefano F, Fanson KV, Endler JA, Biro PA (2019) Behavioral, energetic, and color trait integration in male guppies: testing the melanocortin hypothesis. Behav Ecol 30:1539-1547

Schielzeth H (2010) Simple means to improve the interpretability of regression coefficients. Methods Ecol Evol 1:103-113

Schweitzer C, Motreuil S, Dechaume-Moncharmont FX (2015) Coloration reflects behavioural types in the convict cichlid, Amatitlania siquia. Anim Behav 105:201-209

Seddon N, Botero CA, Tobias JA, Dunn PO, MacGregor HE, Rubenstein DR, Uy JAC, Weir JT, Whittingham LA, Safran RJ (2013) Sexual selection accelerates signal evolution during speciation in birds. Proc R Soc B 280:20131065

Stoehr AM, Kokko H (2006) Sexual dimorphism in immunocompetence: what does life-history theory predict? Behav Ecol 17:751-756

Stoffel MA, Nakagawa S, Schielzeth H (2017) rptR: repeatability estimation and variance decomposition by generalized linear mixed-effects models. Methods Ecol Evol 8:1639-1644

Stuber EF, Araya-Ajoy YG, Mathot KJ, Mutzel A, Nicolaus M, Wijmenga JJ, Mueller JC, Dingemanse NJ (2013) Slow explorers take less risk: a problem of sampling bias in ecological studies. Behav Ecol 24:1092-1098

Summers-Smith JD (1995) The tree sparrow. Poyser, London

Svobodová J, Bauerová $\mathrm{P}$, Eliáš J, Velová $\mathrm{H}$, Vinkler M, Albrecht T (2018) Sperm variation in great tit males (Parus major) is linked to a haematological health-related trait, but not ornamentation. $\mathrm{J}$ Ornithol 159:815-822

Svobodová J, Gabrielová B, Synek P, Marsik P, Vaněk T, Albrecht T, Vinkler M (2013) The health signalling of ornamental traits in the Grey Partridge (Perdix perdix). J Ornithol 154:717-725

Thys B, Pinxten R, Eens M (2020) Does the tie fit the female? Melaninbased colouration, aggressive personality and reproductive investment in female great tits (Parus major). Behav Ecol Sociobiol 74:43

Thys B, Pinxten R, Raap T, De Meester G, Rivera-Gutierrez HF, Eens M (2017) The female perspective of personality in a wild songbird: repeatable aggressiveness relates to exploration behaviour. Sci Rep 7:7656

Tibbetts EA, Dale J (2004) A socially enforced signal of quality in a paper wasp. Nature 432:218-222

Tibbetts EA, Safran RJ (2009) Co-evolution of plumage characteristics and winter sociality in New and Old World sparrows. J Evol Biol 22:2376-2386

Tobias JA, Montgomerie R, Lyon BE (2012) The evolution of female ornaments and weaponry: social selection, sexual selection and ecological competition. Philos Trans R Soc B 367:2274-2293

Torda G, Liker A, Barta Z (2004) Dominance hierarchy and status signalling in captive tree sparrow (Passer montanus) flocks. Acta Zool Acad Sci H 50:35-44

Van Duyse E, Pinxten R, Eens M (2003) Seasonal fluctuations in plasma testosterone levels and diurnal song activity in free-living male great tits. Gen Comp Endocrinol 134:1-9

Weiss SL (2006) Female-specific color is a signal of quality in the striped plateau lizard (Sceloporus virgatus). Behav Ecol 17:726-732

Weiss SL, Kennedy EA, Bernhard JA (2009) Female-specific ornamentation predicts offspring quality in the striped plateau lizard, Sceloporus virgatus. Behav Ecol 20:1063-1071

West PM, Packer C (2002) Sexual selection, temperature, and the lion's mane. Science 297:1339-1343

Wolak ME, Fairbairn DJ, Paulsen YR (2012) Guidelines for estimating repeatability. Methods Ecol Evol 3:129-137

Publisher's note Springer Nature remains neutral with regard to jurisdictional claims in published maps and institutional affiliations. 